\title{
Percepção de pacientes sobre a privacidade no hospital
}

\author{
Patients' perception about privacy in the hospital \\ Percepción de pacientes acerca de la privacidad en el hospital
}

Jussara Simone Lenzi Pupulim', Namie Okino Sawada"

'Universidade Estadual de Maringá, Departamento de Enfermagem, Área de saúde do adulto e idoso. Maringá-PR, Brasil. "Universidade de São Paulo, Escola de Enfermagem. Ribeirão Preto-SP, Brasil.

\author{
Submissão: 14-01-2010 Aprovação: 03-10-2012
}

\section{RESUMO}

Estudo qualitativo empregando a análise de conteúdo, objetivando descrever a percepção de privacidade do paciente hospitalizado. Participaram 34 pacientes internados há, pelo mínimo, 3 dias. A análise das informações, fundamentada no referencial teórico da privacidade, evidenciou 3 categorias temáticas: dignidade e respeito, autonomia, espaço pessoal e territorial. Os sujeitos apontaram fatores comportamentais que contribuem ou não para a proteção e manutenção da privacidade no hospital, destacando o respeito como aspecto mais importante, seguido pelo controle pessoal sobre situações que transgridem sua privacidade. Para eles privacidade está interligada com dignidade e respeito, depende da demarcação do espaço pessoal/ territorial e da garantia de autonomia, estando esses conceitos e atitudes inter-relacionados e sendo imprescindíveis para o resguardo da privacidade no ambiente hospitalar.

Descritores: Assistência ao Paciente; Hospitalização; Privacidade; Autonomia Pessoal; Espaço Pessoal.

ABSTRACT
This qualitative study aimed to describe the hospitalized patient's perception on privacy, using the content analysis. Thirty-four patients, who have been at least three days hospitalized, participated in the study. The analysis of the information was based on the theoretical reference framework of privacy, and evidenced three thematic categories: dignity and respect, autonomy, personal and territorial space. The subjects pointed out behavioral factors, which contribute or not for the protection and maintenance of the privacy in the hospital, highlighting respect as the most important aspect, followed by personal control over situations that violate privacy. Patients believe that privacy is linked to dignity and respect, depends on the demarcation of the personal/territorial space and the autonomy's security; and that these concepts and attitudes are connected and essential to protect privacy in the hospital context.

Key words: Patient Care; Hospitalization; Privacy; Personal Autonomy; Personal Space.

\section{RESUMEN}

Este estudio cualitativo que tuvo el objetivo de describir la percepción de privacidad del paciente hospitalizado, utilizando el análisis de contenido. Participaran 34 pacientes que estuvieron internos por un mínimo de tres días. El análisis de las informaciones, fundamentada en el referencial teórico de la privacidad, evidenció tres categorías temáticas: dignidad y respeto, autonomía, espacio personal y territorial. Los sujetos señalaran factores comportamentales que contribuyen o no para la protección y manutención de la privacidad en el hospital, destacando el respeto como aspecto más importante, seguido por el control personal sobre situaciones que trasgreden su privacidad. Para ellos privacidad está interconectada con dignidad y respeto, depende de la demarcación del espacio personal/territorial y de la garantía de autonomía, tales conceptos y actitudes están relacionados y son imprescindibles para el resguardo de la privacidad en el ambiente hospitalario.

Palabras clave: Atención al Paciente; Hospitalización; Privacidad; Autonomía Personal; Espacio Personal.

Artigo extraído da Tese (Doutorado) "Satisfação do paciente hospitalizado com sua privacidade física: construção e validação de um instrumento de medida", apresentada, em 2009, à Universidade de São Paulo, Escola de Enfermagem de Ribeirão Preto, Programa de Pós-Graduação em Enfermagem Fundamental. 


\section{INTRODUÇÃO}

O hospital é um ambiente hostil à natureza humana por potencializar fragilidade física e vulnerabilidade emocional ante o processo saúde-doença. Ao confrontar a doença e o tratamento, os pacientes se deparam com circunstâncias que interferem no seu estilo de vida, somando-se a convivência com pessoas que não fazem parte da sua estrutura social. Consequentemente, a hospitalização requer aceitação, adaptação, submissão e resignação.

Neste cenário, geralmente o paciente compartilha o mesmo espaço com outros pacientes e com os profissionais. Equipe de enfermagem, nutricionistas, fisioterapeutas, médicos, psicólogos, assistentes sociais, profissionais dos serviços de exames complementares e dos serviços de apoio (manutenção, limpeza, recepção, etc.) circulam livremente no ambiente hospitalar e tem acesso direto e contínuo aos pacientes, sem contar a presença alternativa e intermitente de estudantes universitários e pesquisadores. De tal modo, a ausência de privacidade é uma realidade constante.

É reconhecível que o paciente tem sua privacidade comprometida ao dar entrada no hospital, o que se acentua conforme a gravidade da doença e o grau de dependência dos cuidados. Ainda, a estrutura física e administrativa, somando-se as limitações práticas, pode dificultar o resguardo da privacidade dos pacientes, cuja responsabilidade é da equipe de saúde, sobretudo da enfermagem.

Por outro lado, como exercer a prática assistencial sem infringir a privacidade do paciente? Sabe-se que, inevitavelmente, essa será afetada, mas pergunta-se: em que medida? de que maneira? O que se observa é que os pacientes se sentem desconfortáveis em fornecer tantos dados sobre si, desde o serviço de recepção e admissão do hospital até sua acomodação no leito hospitalar, como também por ter seu corpo submetido e exposto às várias atividades assistenciais e que se repetem nos dias subsequentes. Em adição, a maioria da população brasileira não tem acesso a quartos individuais, dividindo enfermarias com pessoas desconhecidas, situação que se complica quando necessário desnudar e tocar o corpo, além de trocar informações.

De certa forma, quando as pessoas procuram um serviço de saúde estão preparadas para esse tipo de invasão, mas não estão preparadas para lidar com a forma como isso, muitas vezes, acontece. O hospital é uma instituição de caráter social e público e, portanto, envolve expectativas de como as pessoas deveriam interagir umas com as outras. Nesse caso, o relacionamento profissional-paciente é de extrema importância, especialmente com a enfermagem, pois quando estabelece confiança com o profissional o paciente fica mais à vontade para se expor, emocional e fisicamente, para dar informações pessoais e até sobre as pretensões quanto à privacidade.

Privacidade não é somente excluir-se ou o artifício de deixar aproximar-se, envolve estar em contato ou sem contato com os outros. O desejo por interação social ou não altera-se com o tempo e as circunstâncias ${ }^{(1)}$, pois privacidade consiste no afastamento temporário e voluntário de uma pessoa, da sociedade em geral, por meios físicos ou psicológicos ${ }^{(2)} \mathrm{e}$ incide em ter o controle seletivo do acesso a si próprio, ou melhor, em um processo dinâmico de regulação da fronteira interpessoal, por meio do qual os indivíduos ou grupos podem controlar ou regular a interação ${ }^{(1)}$.

Infelizmente, nos serviços de saúde a doença monopoliza a atenção dos profissionais, priorizando-se as medidas para conter a enfermidade, ficando o respeito, a individualidade, a dignidade, os direitos do paciente, suas preferências, valores, crenças, costumes e sentimentos em segundo plano. Isso reflete na assistência como impessoalidade, insensibilidade e mecanização, embora a racionalização, a técnica e conhecimento científico sejam imprescindíveis nesse contexto.

Considerando as atividades assistenciais e a suposição que os pacientes se importam com a invasão da privacidade, acredita-se que conhecer suas preferências relativas à privacidade, identificar os aspectos intervenientes e as implicações decorrentes da violação da privacidade, contribuirá para a adoção de condutas e medidas que assegurem sua proteção no hospital. Diante do exposto e que o conceito de privacidade é complexo e envolve diferentes perspectivas e dimensões culturais, tanto que não há consenso universal sobre sua concepção( ${ }^{(3)}$, o presente estudo teve por objetivo descrever a percepção de privacidade do paciente no contexto hospitalar.

\section{METODOLOGIA}

Este artigo é parte da tese de doutorado intitulada "Satisfação do paciente hospitalizado com sua privacidade física: construção e validação de um instrumento de medida", cuja pesquisa foi desenvolvida após aprovação de Comitê de Ética em Pesquisa Envolvendo Seres Humanos (Parecer 084/2007), concordância e assinatura do Termo de Consentimento Livre e Esclarecido pelos sujeitos do estudo (Resolução no 196/96). Embora o foco principal da pesquisa seja a privacidade física referente à exposição e manipulação corporal durante a assistência, a concepção sobre privacidade em geral emitida pelos pacientes internados merece ser discutida separadamente, optando-se nesse manuscrito por abordar tal enfoque.

Trata-se de um estudo descritivo, com abordagem metodológica qualitativa usando a análise de conteúdo ${ }^{(4)}$, modalidade temática, para se identificar nas falas dos sujeitos os caracteres comuns, cuja presença e/ou frequência tivesse significado para o objetivo analítico visado. Dessa forma buscou-se identificar o sentido dos conteúdos emitidos nas mensagens (núcleos de sentido), a fim de se extrair as categorias temáticas, cujos significados expressam a percepção dos pacientes sobre a privacidade.

Para tanto, após leituras repetidas das entrevistas obtidas, procedeu-se com o isolamento e classificação dos elementos, ordenando-os e agrupando-os conforme a similaridade, no intuito inicial de obter "uma representatividade simplificada dos dados brutos" ${ }^{\prime \prime)}$. Em seguida, procedeu-se com os recortes das mensagens em nível semântico (unidades de registro), as quais foram codificadas com um número (indicando o sujeito) e uma letra maiúscula (indicando a fala). Os dados correspondentes foram compilados em categorias temáticas segundo a similaridade, presença e frequência, e norteadas por Teorias da Privacidade ${ }^{(1-2)}$, referencial teórico adotado para o estudo. 
A coleta de dados prosseguiu até a saturação das informações, no período de 15 de abril a 25 de maio de 2007, com pacientes hospitalizados por no mínimo 3 dias nas diversas unidades de internação de 6 hospitais do município de Maringá-PR (2 públicos, 3 privados e 1 filantrópico). Participaram 34 pacientes com idade igual ou superior a 18 anos, de ambos os sexos, conscientes e orientados, caracterizados quanto à faixa etária, sexo, religião, cor da pele, estado civil, renda familiar, nível de escolaridade, e quanto ao número de hospitalizações, tempo da internação atual e nível de dependência ${ }^{(5)}$.

Os pacientes foram contatados e entrevistados no período de internação. O nível de dependência foi avaliado quanto à natureza em total ou parcial, e quanto "à extensão qualitativa em Total-Fazer e Parcial-Ajudar, Orientar, Supervisionar e Encaminhar" (FAOSE). Tal classificação dimensiona quantitativamente a dependência em graus, cujos valores atribuídos neste estudo foram baixa dependência (1), média dependência (2), alta dependência (3) e totalmente dependente $(4)^{(5)}$.
Os dados foram coletados por meio de entrevista semiestruturada, orientada pela questão aberto-fechada: "O que é para o (a) senhor (a) privacidade dentro do hospital?". As entrevistas foram registradas por escrito pela pesquisadora e, ao término de cada encontro, transcritas e codificadas. A pergunta foi lida para o sujeito e as dúvidas esclarecidas, orientando no sentido de explorar profundamente o tema para se conseguir o máximo de informações a partir da questão norteadora, sem induzir a resposta. Ao final, as anotações foram lidas para possíveis complementações, retificações e confirmação das informações.

\section{RESULTADOS E DISCUSSÃO}

A caracterização sócio-demográfica dos 34 sujeitos (Tabela 1) mostra predomínio de pacientes casados $(58,8 \%)$, católicos $(70,6 \%)$ e de cor branca $(67,6 \%)$. A maioria tem baixo nível de escolaridade e renda familiar inferior a cinco salários mínimos, observando-se equivalência em relação ao sexo e à faixa etária.

Tabela 1 - Caracterização sócio-demográfica dos pacientes internados nos hospitais de Maringá. Maringá-PR, 2007.

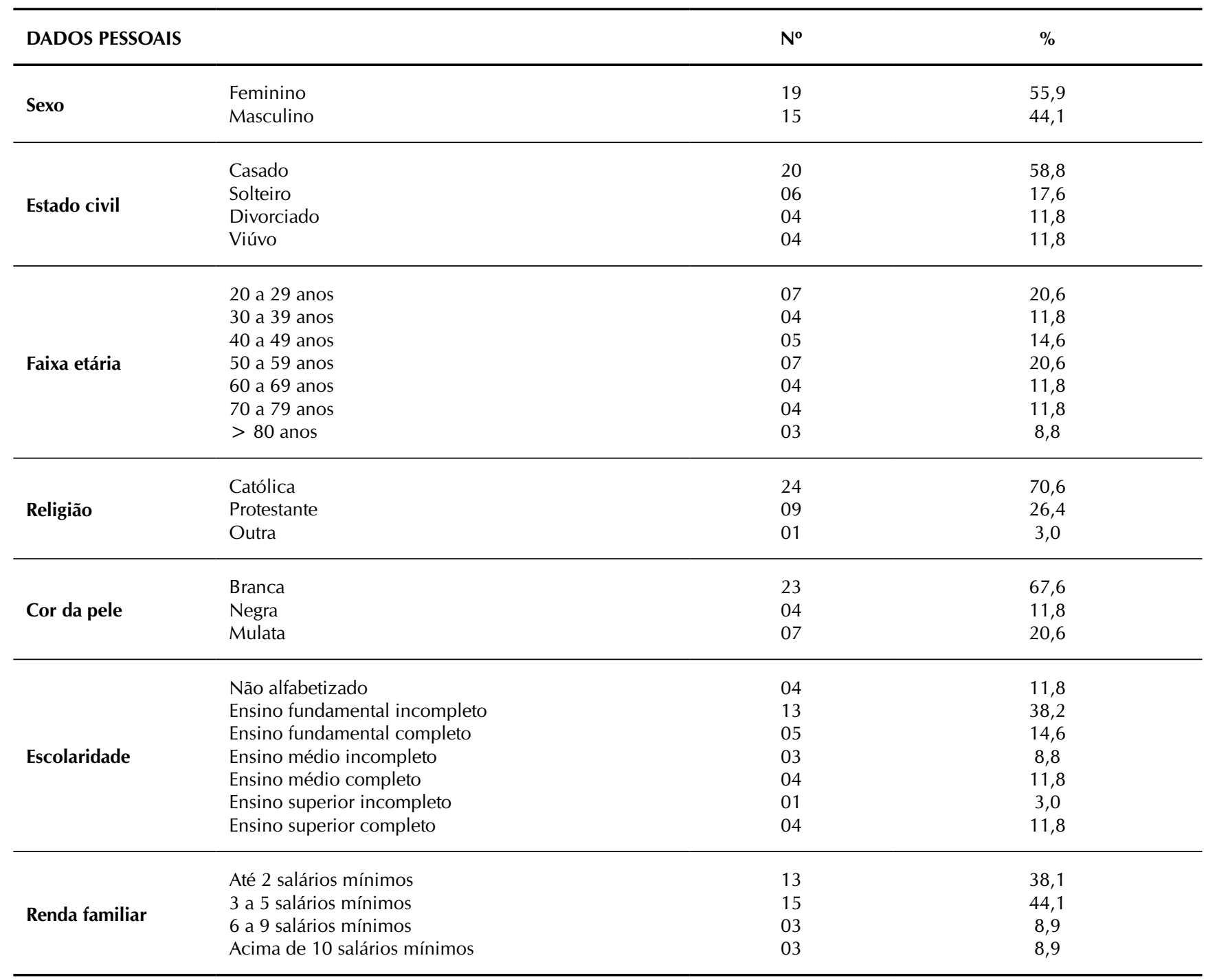


Tabela 2 - Caracterização dos 34 pacientes referente ao período de internação. Maringá-PR, 2007.

\begin{tabular}{llll}
\hline DADOS DE HOSPITALIZAÇÃO & & No & \% \\
\hline \multirow{3}{*}{ Tempo de Internação Atual } & 3 a 6 dias & 21 & 61,8 \\
& 7 a 10 dias & 08 & 23,5 \\
& 11 dias ou mais & 05 & 14,7 \\
Número de internações & 1 a 3 vezes & 20 & 58,8 \\
& 4 a 7 vezes & 07 & 20,6 \\
Nível de dependência & 8 vezes ou mais & 07 & 20,6 \\
& Baixo & 18 & 53,0 \\
& Médio & 10 & 29,4 \\
& Alto & 06 & 17,6 \\
\hline
\end{tabular}

A Tabela 2 apresenta a caracterização referente ao período de internação e evidencia que a maioria esteve hospitalizada por menos de seis dias $(61,8 \%)$, não vivenciava a primeira internação e era pouco dependente (53\%). Observou-se que tanto os pacientes com várias experiências em internamento como os que vivenciam a primeira ou segunda internação manifestaram apreensões e expectativas similares com relação à privacidade. $\mathrm{O}$ mesmo também foi percebido com referência à idade, ao estado civil, à religião, ao nível de escolaridade e condições socioeconômicas. Todavia, nota-se que, na medida em que se prolongam os dias de internamento, e quanto mais dependente dos cuidados, os pacientes são mais enfáticos a respeito das transgressões contra sua privacidade, provavelmente por estarem mais sujeitos às ações dos profissionais e às circunstâncias que os predispõem a isso.

Estas observações podem ser constatadas na apresentação e discussão dos resultados, cuja análise das informações obtidas nas entrevistas permitiu identificar três categorias temáticas, fundamentadas no referencial teórico, oriundas da visão dos pacientes sobre a privacidade em geral no contexto hospitalar, sendo dignidade e respeito, autonomia e espaço pessoal e territorial.

\section{A. Dignidade e respeito}

As falas que originaram essa categoria reportam-se à imagem que os pacientes têm de um cuidado de qualidade, ao respeito e à moralidade que devem estar presentes nas várias situações vivenciadas, no sentido de preservar sua privacidade contra a intrusão indesejada. Para os sujeitos, tal percepção parece estar vinculada à necessidade de ser visto como pessoa, ser humano, e não como objeto. Ao mesmo tempo, entende-se que seus sentimentos e reações devem ser observados e valorizados, pois a falta de privacidade provavelmente acarretará desconforto e insatisfação com o cuidado.

Isso pode ser evidenciado quando vários pacientes relacionam o fato de ser bem cuidado, bem tratado e atendido, além de destacarem a educação e atenção dos profissionais, como fatores que influenciam as medidas para a proteção e manutenção da privacidade.
[...] somos respeitados nos nossos desejos na medida do possível, atendem bem, são educados. (8A)

[...] é respeitar o outro, é cuidar bem. (15A, 32A)

É quando respeitam a gente, dão atenção. (16A)

A privacidade é muito boa, cuidam bem. (26A, 27A, 29A)

Estudos sobre satisfação com os cuidados evidenciaram que receber atenção e ser bem atendido, incluindo manter a privacidade, melhora a percepção dos pacientes sobre o cuidado e, por conseguinte, sua dignidade ${ }^{(6)}$. Dignidade e privacidade conferem qualidade à assistência, sendo essas de responsabilidade dos profissionais ao realizar as atividades de cuidado, bem como manter a individualidade e o respeito à privacidade são aspectos considerados essenciais à promoção do conforto no hospital ${ }^{(7-8)}$.

Em concordância, um estudo descreveu que na concepção de pacientes a dignidade está relacionada ao tratamento que recebem dos cuidadores, pois a forma como são tratados pode comprometer o sentido de dignidade, como ser visto como pessoa, digno de confiança e de respeito, e que essa envolve aspectos da privacidade ${ }^{(9)}$. Os pacientes reforçam essa visão quando alegam que a privacidade consiste em respeitar suas preferências com relação à privacidade, respeitá-lo como indivíduo e considerar seus limites.

Privacidade é respeitar o outro, as nossas vontades. Se não quero tomar banho, tem que respeitar. (12A)

É ser respeitado aqui dentro. (31A)

É o limite até onde o paciente pode e é respeitado. (34A)

Tais colocações deixam claro que gostariam que suas preferências fossem observadas e supridas pelos profissionais, segundo suas crenças e valores pessoais. Para tal, faz-se imprescindível a sensibilidade, a solidariedade e o respeito dos que cuidam para com quem é cuidado, sobretudo com 
aqueles sem condições de cuidar de si. Concepções similares foram emitidas por outro grupo de pacientes, para os quais dignidade é uma característica inerente ao ser humano, que pode ser subjetivamente expressada como um atributo do self e por comportamentos que demonstram respeito por si e pelos outros ${ }^{(7)}$.

Na verdade, dignidade está presente quando um indivíduo é capaz de controlar seu comportamento, o meio ambiente e o modo como é tratado pelos outros, ou mesmo a habilidade para sentir-se valorizado em relação aos outros, pois a dignidade humana incorpora muitas características da privacidade $^{(10)}$. Isto é visível quando os pacientes advertem que a privacidade engloba respeito ao seu espaço, ao seu corpo, bem como a não divulgação dos dados pessoais.

Privacidade é respeitar o paciente quando entram no quarto e vem examinar a gente. (13A)

O hospital respeita minha privacidade não divulgando minha patologia. (19A)

O sentido de dignidade e respeito emitido pelos pacientes envolve aspectos como acreditar em si mesmo, poder confiar na interação com os profissionais e que isso será recíproco, além do que se a equipe for sensível a seus sentimentos se preocupará com sua privacidade. De fato, os significados atribuídos mostram que o desrespeito à privacidade, ou ausência dela, afeta o bem-estar, e, portanto, a dignidade. Vale lembrar que a idéia central do componente comportamental de dignidade está relacionada à ação que mostra respeito, assim, a dignidade pode ser afetada pelo tratamento que se recebe dos outros ${ }^{(7)}$.

É visível que o respeito emerge como fator indispensável para o processo de cuidar em saúde e está diretamente vinculado à proteção e manutenção da privacidade ${ }^{(11-12)}$. Desse modo, entende-se o respeito como um dos fundamentos da moralidade e da ética, necessário no relacionamento interpessoal e imperioso no exercício profissional.

Por outro lado, surpreende que apenas um sujeito tenha se referido à privacidade informacional, visto que o sigilo sobre o diagnóstico e a discrição quanto ao tratamento são preocupações comuns entre os pacientes, principalmente naqueles alocados em enfermarias. A suposta importância à confidencialidade dos dados não foi manifestada por esse grupo de pacientes, talvez por estarem mais incomodados com os demais fatores associados à privacidade e que no seu entender merecem maior atenção. Acredita-se que os pacientes apontaram aqueles que geram mais inquietação, desconforto e inconveniência.

Na mesma vertente, o respeito à integridade do paciente é visto como condição de totalidade, no qual os desejos e valores individuais de cada pessoa, evoluídos a partir da experiência com a doença e suas consequências, devem ser sempre considerados. Desse modo, o respeito à autodeterminação do paciente implica no direito dele de tomar suas próprias decisões e agir conforme seus valores e anseios pessoais, mantendo sua dignidade, desde que não interfira com o direito de outra pessoa ${ }^{(8)}$.

\section{B. Autonomia}

Essa categoria incluiu as falas que denotam ter controle sobre sua própria pessoa e sobre a situação, bem como sobre os aspectos ou fatores que interferem na manutenção da sua privacidade. Um teorista define privacidade como controle seletivo, ou regulação, do acesso a si por outras pessoas ${ }^{(1)}$; e outro como afastamento das outras pessoas determinando em que medida se está acessível, sendo que a autonomia pessoal caracteriza-se como uma das funções da privacidade ${ }^{(2)}$.

De fato, alguns pacientes indicam que solicitar para manipular seu corpo, para examinar ou outro cuidado/procedimento, demonstra consideração e atenção, fazendo com que se sintam valorizados e no comando da situação. Talvez isso minimize os efeitos da invasão e a sensação de ser visto como objeto.

Privacidade é pedir autorização na hora de mexer com a gente. (15B)

\section{[...] é não ser incomodado. (1B, 15D)}

\section{[...] é ter silêncio. (14A)}

Privacidade é não mudar os hábitos de casa. (20A)

\section{[...] é deixar você fazer suas coisas em paz, não ficar no seu pé toda hora. (31B)}

O alerta quanto a pedir permissão para abordá-los mostra que tal conduta faz com que se sintam valorizados como um indivíduo único, com suas peculiaridades, e que a situação está sob seu domínio. Essa atitude, assim como o respeito, confere dignidade na visão dos pacientes quando se trata da privacidade. Em contrapartida, essas observações também sugerem negligência por parte do profissional com relação à sua preferência por privacidade em certos eventos e falta de consideração por parte de outros. Quando citam o fato de pedir autorização para tocar o seu corpo advertem que são donos de si e responsáveis por seu próprio corpo, mesmo que fragilizados pela doença. Nesse sentido, a dignidade configura respeito e preservação da própria identidade moral e da autonomia, e quando se refere à privacidade entende-se que com a permissão da pessoa não há violação, e, portanto, não há perda da dignidade ${ }^{(13)}$.

Constata-se que os pacientes manifestam anseio por um pouco de isolamento, de solidão, de períodos de circunspeção, o que esporadicamente conseguem em seu lar e que no hospital é praticamente impossível. Alguns transmitem a idéia de que seu direito à opção e à sua preferência foi tolhido durante a hospitalização e que a forma como realmente gostariam que fosse não é viável, e que isso é consequência da mudança de ambiente. O fato de estar no hospital, um local diferente e que não é de seu domínio, interfere na sua habilidade de controlar sua privacidade. Tal visão é apoiada pela observação de que ao se internar o paciente nem sempre é capaz de reter o controle de sua própria necessidade por privacidade ${ }^{(14)}$. 
Definir privacidade como controle relaciona-a ao poder de ter determinadas escolhas ao invés da opção por meios pelos quais se pode exercer tal poder ${ }^{(3)}$. Percebe-se que os pacientes expressam suas preferências e ambicionam ter mais controle em dadas situações, porém se conformam, aparentemente sem buscar alternativas. Na verdade, é reconhecível que o paciente hospitalizado tem pouca chance para controlar o ambiente e frequentemente vivencia a perda da privacidade, o que pode ser observado nas colocações que evidenciam a ausência de liberdade pessoal e a falta de condições para manter sua privacidade no hospital.

\section{[...] no hospital não tem privacidade. (4A)}

Meu direito de ir e vir foi parcialmente restrito. (21A)

Privacidade não existe de jeito nenhum. (28A)

O respeito à autonomia do paciente significa dar a ele a oportunidade de escolher, pois a percepção de controle transmite segurança e, portanto, se sentem menos ameaçados ${ }^{(8-9)}$. Aparentemente, a manutenção da privacidade permite um sentimento de controle individual e de expressão de autonomia. Outro estudo sobre privacidade e direitos dos pacientes também identificou a categoria controle e opção individual, e constatou que a autonomia deles foi frequentemente corroída pelas atitudes e comportamentos da equipe de saúde, deflagrando a perda do controle e de escolha ${ }^{(10)}$.

Essa visão corrobora com a colocação de que a autonomia pode ser entendida como o interesse do indivíduo em tomar decisões significativas sobre sua vida, pois um estudo no contexto da interação profissional-paciente identificou que a compreensão conceitual de autonomia em combinação com integridade (envolvendo dignidade e privacidade), consiste na habilidade e liberdade para tomar decisões sem coerção ou restrição externa ${ }^{(8)}$. Nesse sentido, admite-se a relação entre autonomia e a necessidade de privacidade no hospital manifestada pelos pacientes. A menção à autonomia também é reforçada quando surgem reivindicações por espaço pessoal e território, terceira categoria identificada.

\section{Espaço pessoal e territorial}

A última categoria identificada englobou as falas dos sujeitos que revelaram sua necessidade por um local só seu, próprio, particular, como uma forma de obter um pouco de reclusão e tranquilidade, na tentativa de preservar-se e resgatar sua individualidade. O espaço pessoal é um ponto invisível que circunda o corpo humano, uma área individual que separa uma pessoa de outras pessoas, um tipo de zona de proteção ${ }^{(3)}$, e território é uma área que um indivíduo defende como sendo exclusiva $^{(2)}$. Já a territorialidade é um termo usado para descrever a condição de possessividade, controle, autoridade sobre uma área do espaço físico ${ }^{(1)}$.

De acordo com os sujeitos, ao reclamarem um local para si, mantendo-se à parte dos outros pacientes, revelam que gostariam de isolamento e que prefeririam não compartilhar a mesma enfermaria. É nítido o desconforto de alguns pacientes com a presença de outros no mesmo quarto, pois isto significa dividir não apenas espaço, mas também aspectos da esfera pessoal, desde conversas com visitas e profissionais até o repouso, higiene e outras atividades.

Privacidade é a condição de ficar no seu local. (1A)

[...] é estar em um quarto sozinho. (5A)

[...] é ter o meu cantinho. (10A)

[...] é não ter muita gente dormindo perto de você. (11B)

\section{[...] é ficar quietinho no nosso canto. (15C)}

Privacidade dentro do hospital é ninguém tomar o espaço da gente. (18A)

A mesma reivindicação foi observada em outro estudo, no qual os pacientes igualmente manifestaram querer ficar sozinhos, ter a possibilidade de privacidade sem outras pessoas em volta ${ }^{(9)}$. Uma investigação sobre a percepção de privacidade de pacientes em quartos compartilhados, em hospitais na Nova Zelândia, averiguou que os pacientes determinam a necessidade por uma área privada para manter o controle sobre as informações pessoais e para evitar a exposição física, mesmo quando a separação entre os leitos é proporcionada por cortinas ${ }^{(15)}$.

Infelizmente, apenas uma parcela da população tem o privilégio de se internar em quarto individual, não só no Brasil como em outras locais. Sabe-se que em alguns países enfermarias dos serviços de emergência e em UTIs podem ser mistas, tendo os leitos ou Box separados por cortinas ou divisórias. Assim, além de dividir o mesmo ambiente os pacientes às vezes também convivem com pacientes de sexo diferente ao $\operatorname{seu}^{(15)}$, situação essa não muito diferente da brasileira. Privacidade implica territorialidade, a qual está presente em muitas espécies, incluindo o ser humano, e consiste em proteger um território contra a intrusão de outros. Para os homens a defesa de uma área, de uma propriedade, não consiste somente conservar a terra ou espaço, mas também objetos, ideias, privilégios ou direitos.

Portanto, território é aquela área da vida do indivíduo que ele vivencia como sua e na qual exerce controle, toma iniciativa, é especialista ou pela qual aceita responsabilidade ${ }^{(1)}$. Quando a pessoa tem um lugar só seu ela se sente mais segura e tem a sensação de que assim restringe a circulação de outras pessoas em volta de si. Alguns sujeitos indicam que o ingresso de pessoas em seu quarto transgride sua privacidade, percebendo-se nos relatos que muitas vezes o que mais aborrece é a forma como os profissionais infringem seu espaço físico.

\section{[...] as pessoas entram e saem a toda hora. (4B)}

[...] a pessoa chega a qualquer hora, de madrugada. (11A)

O controle do espaço físico é crucial para o bem-estar 
físico e psicológico de todas as pessoas, principalmente no ambiente hospitalar onde o trânsito de pessoas é constante por se tratar de um local público, mas que implica doença. Alerta-se que a invasão desnecessária desse espaço pela equipe de saúde, ou outras pessoas, é inadequada, pois o que pode parecer justificado para alguns, para outros pode ser visto como violação da privacidade ${ }^{(10)}$. Isso ocorre porque o comportamento territorial é influenciado por fatores culturais e também porque as pessoas entendem a invasão do espaço pessoal como inevitável quando estão doentes, porém não compreendem a necessidade excessiva de ter seu espaço físico invadido.

No mesmo sentido, uma pesquisa identificou junto a pacientes hospitalizados seis componentes de invasão do espaço territorial, sendo "desrespeito ao espaço físico, interrupção do sono e descanso, descontrole do espaço físico, descaso para com o espaço físico, mudança do espaço físico sem consulta e entrada no espaço físico sem permissão"(16). O que de fato acontece é que os profissionais agem como se este território fosse exclusivo da equipe de saúde, aprovado e legitimado pela sociedade para estar dentre as paredes do hospital. No entanto, os próprios deveriam respeitar o espaço do paciente e seu direito à privacidade, embora se reconheça que é impossível realizar o cuidado sem invasão do território, do espaço e da zona corporal.

A hospitalização submete o paciente à intrusão do espaço pessoal e territorial, o que gera ameaça à sua dignidade, à sua integridade. Nesse ambiente a intrusão/invasão pode ser definida como entrada e atividade ou contato não solicitados, o espaço pessoal como uma área que se estende exteriormente (de fora para dentro) a uma distância de cerca de $120 \mathrm{~cm}$ do corpo da pessoa, e território como a área do quarto do hospital que é reivindicada pelo paciente ${ }^{(16)}$.

Desse modo, o banheiro, elemento para o qual alguns pacientes alertaram, também faz parte do território, sobretudo quando o estão ocupando. Em geral, os pacientes são orientados a não trancar a porta do banheiro quando lá estão pela possibilidade de sentirem-se mal, facilitando o acesso da equipe caso necessário. Contudo, com frequência são interrompidos e sua privacidade é infringida.

Privacidade é ter o banheiro com a porta fechada quando precisar ir. (22A) Privacidade é no banheiro, tendo a porta encostada. (23A)

Outros estudos também revelam que a privacidade no banheiro é essencial para os pacientes ${ }^{(14,16)}$. Há de se reconhecer o quanto é desagradável abrirem a porta do banheiro quando o mesmo está sendo usado, dado que esse ambiente envolve atividades de cunho extremamente pessoal. A intromissão de outros no quarto e banheiro do paciente é reconhecidamente invasão da privacidade. O que os pacientes requerem é impedir o trânsito de pessoas nesses momentos, como fechar a porta e colocar um aviso. A ansiedade do paciente provocada pela probabilidade de alguém entrar e surpreendê-lo em situação constrangedora é plausível, ainda mais quando enfatizam os problemas com o banheiro.
Admite-se que a enfermagem repetidamente invade o espaço pessoal e territorial do paciente por falha em avisar antes de exceder os limites, por sobrecarga de trabalho ou pela dificuldade em superar os obstáculos e a deficiência de recursos $^{(15-17)}$. Destaca-se que a territorialidade provê segurança, privacidade, autonomia e identidade ao indivíduo, logo, é compreensível que o paciente vislumbre a invasão como uma ameaça à sua integridade física e emocional.

O que se percebe é que os pacientes demarcam um território imaginário, porém não expressam sua necessidade e nem definem os limites junto à equipe de saúde. Gostariam de delimitar seu espaço, mas não o fazem. Parecem aguardar que os profissionais tomem providência a esse respeito ou se conformam com a situação por ser temporária e necessária. De certa forma os pacientes advertem para quão difícil é proteger e manter sua privacidade em um ambiente onde a circulação de pessoas é constante e que tanto os profissionais como as outras pessoas agem como se entrar e sair fossem normais. Apesar de corriqueiro para a equipe, os pacientes demonstram que sua privacidade é importante e que sua transgressão os afeta em sua dignidade. Implicitamente os pacientes esperam mais empenho dos profissionais, e aqui se entende que cabe mais à enfermagem adotar medidas que os preserve da intromissão dos outros.

Em concordância, um estudo recente sobre a privacidade do paciente em terapia intensiva assinala que na percepção dos profissionais de saúde que ali atuam, os próprios precisam refletir sobre como preservar a privacidade do paciente, adotando medidas e atitudes que assegurem a dignidade dos pacientes durante as ações de cuidado ${ }^{(18)}$.

Por conseguinte, as comissões de ética institucionais, a quem se entende caberia a orientação e supervisão, não observam e nem recomendam medidas para minimizar ou prevenir infrações. Entretanto, o significado de privacidade no contexto da saúde adotado pelo Kennedy Institute of Ethics, sediado em Washington, e aceito por alguns estudiosos da ética no Brasil, consiste na "limitação do acesso às informações de uma dada pessoa, ao acesso à própria pessoa, à sua intimidade, anonimato, segredos, afastamento ou solidão. É a liberdade que o paciente tem de não ser observado sem autorização"(19).

É compreendida ainda como o direito da pessoa de permanecer sozinha, isolada, sem nenhuma perturbação externa e de escolher o tratamento conforme a preferência pessoal, ou seja, é um processo de regulação do acesso a si ou a um grupo pelos outros, a um tempo em particular e em um certo cenário de circunstâncias, ou seja, envolve controlar a quantidade e o tipo de contato que alguém tem com os outros ${ }^{(20)}$. Privacidade não pode ser observada por si, pode-se observar a violação das normas de privacidade, mas somente quando se aprendem primeiro quais são as normas de privacidade em um dado contexto ${ }^{(11)}$. Daí a importância dos comitês e comissões de ética das instituições, dos direitos e deveres do paciente, dos códigos de ética das profissões, do código civil, da declaração dos direitos humanos e da constituição, como mecanismos disponíveis que podem promulgar normas, medidas e até leis direcionadas à proteção da privacidade do indivíduo hospitalizado ${ }^{(11)}$. 
Mesmo que a privacidade seja vastamente reconhecida como um valor importante, nem filósofos e nem juristas foram bem-sucedidos em converter tal valor a um padrão de proteção legal, claramente definido ${ }^{(15)}$. Contudo, embora as fronteiras e limites da privacidade variem de cultura para cultura, a intrusão injustificada comumente engloba a presença física de pessoa indesejada, observações inconvenientes de/ou pelas pessoas, divulgação de informação particular, imprecisa ou ilusória sobre pessoas, e usurpação das decisões pessoais feitas na própria esfera de alguém ${ }^{(3,20)}$. Portando, considerando tais colocações e os resultados encontrados neste estudo, pode-se preservar a privacidade no ambiente hospitalar mostrando respeito pelos desejos, pelo espaço e pelos pertences do paciente.

\section{CONSIDERAÇÕES FINAIS}

Neste estudo os sujeitos apontaram com mais assiduidade os fatores de caráter comportamental que podem interferir na sua privacidade pessoal, como as atitudes de respeito às suas preferências, consideração pela própria autoridade sobre si e pelo espaço que ocupam no hospital, ainda que tenham que dividi-lo com outros pacientes, referindo-se também aos aspectos de cunho mais íntimo (uso do banheiro, ocasião do banho, dormir junto a estranhos, tocar e examinar seu corpo).

Em contrapartida, um único paciente mencionou a questão da confidencialidade das informações, preocupação constante de muitos pesquisadores da área da saúde e estudiosos da ética e bioética. Deduz-se que isso foi pouco citado porque atualmente os profissionais, conscientizados dessa problemática, tomam cuidado e evitam fazer comentários desnecessários em público sobre o paciente, uma vez que isso tem sido amplamente discutido e divulgado por comitês de ética, em eventos, periódicos científicos e pela mídia. Por outro lado, percebe-se que os pacientes discorreram sobre as ocorrências que mais os incomodou e sobre as que sentem que mais infringem sua privacidade, sua intimidade.
Apesar de muito se discutir sobre confidencialidade, pouco se tem avançado com relação à privacidade do paciente dentro do hospital. O que se observa na prática é que nos ambientes de assistência à saúde, em especial no hospital, as transgressões são mais comuns do que as condutas direcionadas à preservação da privacidade dos pacientes.

Concorda-se com a visão desse grupo de pacientes, de que privacidade está interligada com dignidade e respeito, depende de espaço pessoal e territorial e da garantia de autonomia. Em síntese, autonomia, dignidade, respeito, espaço pessoal e territorial, entre outros, são conceitos inter-relacionados, inerentes e imprescindíveis à proteção e manutenção da privacidade dos pacientes não só no hospital como também em todos os outros serviços de atendimento à saúde.

Reconhece-se que manter a privacidade dos pacientes nos estabelecimentos de assistência à saúde, principalmente no hospital, não constitui tarefa fácil para os profissionais e nem para os usuários. Porém, se as questões levantadas e discutidas forem observadas e consideradas pelos profissionais ao realizarem as atividades de cuidado, somando-se o discernimento entre o que seria correto e errado, certamente a sensação de invasão da privacidade será minimizada, mesmo frente à necessidade de exposição e manipulação corporal e, sobretudo, à impossibilidade de permanecer internado em quarto individual.

Sugere-se a realização de estudo similar sobre o tema com outros pacientes em diferentes regiões geográficas e contextos culturais, visto que este estudo retrata apenas a percepção desse grupo de pacientes. Vale destacar que, quando se fala sobre a privacidade dos pacientes, geralmente as pessoas envolvidas lembram primeiramente do sigilo das informações, porém, neste estudo os sujeitos revelaram não ser essa a sua apreensão mais comum, pois se reportaram quase que exclusivamente às outras circunstâncias e comportamentos que violam sua privacidade e geram insatisfação com a qualidade da assistência.

\section{REFERÊNCIAS}

1. Altman I. The environmet and social behavior: privacy, personal space, territory, crowding. Monterey: Brooks/ Cole; 1975.

2. Westin A. Privacy and freedom. New York: Atheneum; 1970.

3. Leino-Kilpi H, Välimäki M, Dassen T, Gasull M, LEMONIDOU C, SCOTT A, ARNDT M. Privacy: a review of the literature. Int J Nurs Stud 2001;38:663-71.

4. Bardin L. Análise de conteúdo. Lisboa: Edições 70; 2000.

5. Horta WA. Processo de Enfermagem. São Paulo (SP): E.P.U./EDUSP; 1979.

6. Moura GMSS, Luce FB. Encontros de serviço e satisfação de clientes em hospitais. Rev Bras Enferm 2004;57(4):434-40.

7. Jacelon CS, Conelly TW, Brown R, Proulx K, VO T. A concept analysis of dignity for older adults. J Adv Nurs 2004;48(1):76-83.
8. Randers I, Matiasson AC. Autonomy and integrity: upholding older adult patients' dignity. J Adv Nurs 2001;45(1):63-71.

9. Widäng I, Fridlund B. Self-respect, dignity and confidence: conceptions of integrity among male patients. J Adv Nurs 2003;42(1):47-56.

10. Woogara J. Patients' privacy of the person and human rights. Nurs Ethics 2005;12(3):273-87.

11. Pupulim JSL, Sawada NO. O cuidado de enfermagem e a invasão da privacidade do doente: uma questão ético-moral. Rev Latino-Am Enferm 2002;10(3):433-8.

12. Pupulim JSL, Sawada NO. Exposição corporal do cliente durante a avaliação física em Unidade de Terapia intensiva. Rev Bras Enferm 2005;58(5):580-5.

13. Gallager A. Dignity and respect for dignity - two key 
health professional values: implications for nursing practice. Nurs Ethics 2004;11(4):587-99.

14. Pupulim JSL, Sawada NO. Privacidade física referente à exposição e manipulação corporal: percepção de pacientes hospitalizados. Texto \& Contexto Enferm 2010;19(1):36-44.

15. Malcolm HA. Does privacy matter? Former patients discuss their perceptions of privacy in shared hospital rooms. Nursing Ethics 2005;12(2):156-66.

16. Sawada NO. O sentimento do paciente hospitalizado frente à invasão de seu espaço territorial e pessoal Ribeirão Preto. Tese [Doutorado em Enfermagem]- Escola de Enfermagem de Ribeirão Preto, Universidade de São Paulo; 1995.
17. Tabak N, Ozon M. The influence of nurses' attitudes, subjective norms and perceived behavioral control on maintaining patients' privacy in a hospital setting. Nurs Ethics 2004;11(4):366-77.

18. Baggio MA, Pomatti DM, Betinelli LA, Erdmann AL. Privacidade em unidade de terapia intensiva: direitos do paciente e implicações para a enfermagem. Rev Bras Enferm 2011;64(1):25-30.

19. Goldin JR, Francisconi CF. Atuação profissional e privacidade [homepage na internet]. [acesso em 10 mar 2007]. Disponível em: <http://www.ufrgs.br/bioetica/privapoi. htm >

20. Pedersen MD. Model for types of privacy by privacy functions. J. Environment Psychol 1999;19:397-405. 